\title{
Seismic anisotropy of temperate ice in polar ice sheets
}

\author{
M.-G. Llorens ${ }^{1, *}$, A. Griera ${ }^{2}$, P.D. Bons ${ }^{3}$, E. Gomez-Rivas ${ }^{4}$, I. Weikusat ${ }^{3,5}$, D. Prior ${ }^{6}$, J. \\ $\operatorname{Kerch}^{5}$ and R.A. Lebensohn ${ }^{7}$ \\ ${ }^{1}$ Geosciences Barcelona, CSIC, Lluis Sole i Sabaris s/n, 08028 Barcelona, Spain. \\ ${ }^{2}$ Departament de Geologia, Universitat Autònoma de Barcelona, 08193 Cerdanyola del Vallès, \\ Barcelona, Spain. \\ ${ }^{3}$ Departament of Geosciences, Eberhard Karls University Tübingen, Wilhemstr. 56, 72074 \\ Tübingen, Germany. \\ ${ }^{4}$ Departament de Mineralogia, Petrologia i Geologia Aplicada, Facultat de Ciències de la Terra, \\ Universitat de Barcelona, Martí i Franquès s/n, 08028 Barcelona, Spain. \\ ${ }^{5}$ Alfred Wegener Institute Helmholtz Centre for Polar and Marine Research. \\ ${ }^{6}$ Department of Geology, University of Otago, 362 Leith Street, Dunedin 9016, New Zealand. \\ ${ }^{7}$ Theoretical Division, Los Alamos National Laboratory, Los Alamos, NM 87545, USA. \\ Corresponding author: Maria-Gema Llorens (mgllorens@ictja.csic.es)
}

DOI: https://doi.org/10.1029/2020JF005714

This manuscript is published in the Journal of Geophysical Research: Earth Surface, 25, 11. This is an author version of the article. For the final copy-edited version, please visit: https://agupubs.onlinelibrary.wiley.com/doi/abs/10.1029/2020JF005714

\section{Key Points:}

- Through numerical simulations we analyze the velocities of seismic $\mathrm{P}$ and $\mathrm{S}$ waves in temperate ice undergoing dynamic recrystallization

- The highest $\mathrm{P}$ wave velocity aligns with the maximum c-axis orientation in pure ice samples, while it does not align when enough water is present

- If water is at high pressure, at the ice-sheet base, the reduction of the $\mathrm{S}$ wave velocity is remarkably stronger than that of the $\mathrm{P}$ wave 


\begin{abstract}
We present a series of simple shear numerical simulations of dynamic recrystallization of twophase non-linear viscous materials that represent temperate ice. Firstly, we investigate the effect of the presence of water on the resulting microstructures and, secondly, how water influences on P-wave $\left(V_{p}\right)$ and fast $\mathrm{S}$-wave $\left(V_{s}\right)$ velocities. Regardless the water percentage, all simulations evolve from a random fabric to a vertical single maximum. For a purely solid aggregate, the highest $V_{p}$ quickly aligns with the maximum c-axis orientation. At the same time, the maximum c-axis development reduces $V_{S}$ in this orientation. When water is present, the developed maximum c-axis orientation is less intense, which results in lower $V_{p}$ and $V_{s}$. At high percentage of water, $V_{p}$ does not align with the maximum c-axis orientation. If the bulk modulus of ice is assumed for the water phase (i.e., implying that water is at high pressure), we find a remarkable decrease of $V_{s}$ while $V_{p}$ remains close to the value for purely solid ice. These results suggest that the decrease in $V_{S}$ observed at the base of the ice sheets could be explained by the presence of water at elevated pressure, which would reside in isolated pockets at grain triple junctions. Under these conditions water would not favor sliding between ice grains. However, if we consider that deformation dominates over recrystallization water pockets get continuously stretched, allowing water films to be located at grain boundaries. This configuration would modify and even overprint the maximum c-axis-dependent orientation and the magnitude of seismic anisotropy.
\end{abstract}

\title{
1 Introduction
}

The ice mass balances of the Antarctic and Greenland ice sheets represent the largest uncertainty for the prediction of future sea-level rise (e.g., IPCC, 2019; Kopp et al., 2017). The mass balance is determined by the ratio between the snow accumulation on the ice sheets and the removal of ice by processes at the ice-sheet margins, such as melting or discharge into the sea. Understanding how ice flows from the accumulation zone to the margins is therefore crucial to correctly estimating potential mass changes of the polar ice sheets (Rignot, 2006; Hanna et al., 2019). Based on ice rheology studies and glacier motion observations it is generally assumed that flow of large masses of ice mainly depends on two mechanisms: (i) the internal deformation by dislocation creep of the ice crystals (Cuffey and Paterson, 2010) and (ii) sliding at the ice-sheet bedrock interface, which takes place only where the ice bed is at the pressure melting point and therefore liquid water is present in the system (Rignot \& Mouginot, 2012; Wolovick et al., 2014; Bons et al. 2018).

Ice sheets on Earth are composed of the mineral ice Ih, which is ductile (Glen, 1955; Duval et al., 1983; Weertman, 1983), i.e., deforms by crystal-plastic process at the near meltingpoint temperatures (usually $\geq 240 \mathrm{~K}$ in Greenland and $\geq 225 \mathrm{~K}$ in Antarctica; Thorsteinsson et al., 1997; Price et al., 2002) and differential stresses typically on the order of $0.1 \mathrm{MPa}$ or less (Cuffey \& Paterson, 2010; Rignot \& Mouginot, 2012; Bons et al., 2018) in these ice sheets. Precipitation on the surface induces a vertical flattening at the upper levels of ice sheets. At greater depth, the deformation changes towards bedrock-parallel flow, called simple shearing, as the shear stress increases from zero at the surface to a maximum at the base of the ice sheet (Hooke \& Hudleston, 1978; Budd \& Jacka, 1989; Hudleston, 2015). Most of the lateral flow of ice towards the margins is thus controlled by simple shear near the base of ice sheets and by sliding at the base, where the ice is not frozen to the bedrock. Estimates of the proportion of ice that is frozen to the bedrock vary considerably (see e.g., MacGregor et al., 2016; Bons et al. 2018). 
Ice Ih has a hexagonal symmetry with a strong mechanical anisotropy due to easy dislocation glide on the basal plane (i.e., plane normal to the c-axis), which requires a stress 60 times lower than that for gliding on other slip systems at the same strain rate (Duval et al. 1983). The easy glide of dislocations through the ice crystal's basal plane results in a progressive development of a crystallographic preferred orientation (CPO), or lattice preferred orientation (LPO). In the geomaterials community CPO is also called fabric, while in the metals community is termed crystallographic texture. A CPO is defined as the statistically preferred orientation of the crystal lattices of a population of grains (Faria et al., 2014). It is characterized by a vertical caxis maximum of the ice polycrystalline aggregate during horizontal shear deformation (Faria et al., 2009; Castelnau et al., 1996; Durand et al., 2009; Llorens et al., 2016a). Therefore, crystal's basal slip is favored at the base of ice sheets (Azuma \& Goto-Azuma, 1996; Castelnau et al., 1996; Llorens et al., 2016b; Faria et al., 2014), where it enhances bedrock-parallel shearing.

Shear localization at the base of the ice sheet is enhanced by the softening of ice here due to the geothermal heat flow (Dahl-Jensen et al., 1998). The effect of heating increases at high temperature because the activation energy for ice deformation increases significantly towards its melting point (Barnes et al., 1971; Souchez et al., 1993; Goldsby \& Kohlstedt, 2001; Kuiper et al., 2020) and because of the potential presence of water (Gudlaugsson et al., 2016). In temperate glaciers, where liquid water coexists with glacier ice, a melt content of $1 \%$ implies an increase in the effective strain rate by a factor of three (Duval, 1977; Lliboutry \& Duval, 1985).

Microstructural studies of ice cores from Antarctica and Greenland indicate that a significant grain size increase and/or crystallographic preferred orientation change occur in basal sections where $\mathrm{T}>262 \mathrm{~K}$. This is interpreted as the onset of faster kinetics associated with premelting (Gow \& Williams, 1976; Gow \& Engelhardt, 2000; NEEM community members, 2013; Weikusat et al., 2017). Ice near the bedrock was found frozen to the bed at the GISP2 and GRIP ice cores. But for the Byrd, EDC, EDML, NEEM and Siple Dome cores the ice was found at, or very close to, the pressure-melting point (Kuiper et al., 2020). In three of these ice cores Byrd (Gow \& Williamson, 1976), EDC (EPICA community members, 2004) and EDML (Wilhelms et al., 2014; Weikusat et al., 2017) - subglacial water was encountered close to the bedrock. However, the study of temperate $\left(T \sim T_{\text {melt }}\right)$ ice is challenging, as current ice core drilling techniques are not suitable to sample this partially molten ice properly. Moreover, experiments are hard to perform in laboratories, and a only few deformation experiments using ice samples at high temperature $\left(>-5^{\circ} \mathrm{C}\right)$ have been carried out to date (Kamb, 1972, Duval, 1977; Wilson \& Russell-Head, 1982). Numerical modelling allows us to go beyond these limitations, as simulations can be utilized to systematically study polycrystalline aggregates that include different percentages of a second phase, such as water (Llorens et al., 2019).

The elastic properties of single ice crystals are anisotropic with a symmetry axis parallel to the crystal c-axis (Gammon et al., 1983), called transverse isotropy (TI). Polycrystalline ice with no crystallographic preferred orientation exhibits no elastic anisotropy. However, with increasing depth, the elastic anisotropy of polycrystalline ice gradually increases due the development of a CPO as a consequence of crystal rotations associated with dislocation creep, and possibly recrystallization, with the c-axis maximum density oriented in the vertical direction (Gillet-Chaulet et al., 2005). Towards the deeper part of the ice sheet, the elastic anisotropy is strongest, and is called vertically symmetric transverse isotropy (VTI). Seismic data are therefore extremely useful for the evaluation of ice flow. The degree of seismic anisotropy and the P-wave 
velocity $\left(V_{p}\right)$ can be considered as a proxy for the crystal orientation (Diez et al., 2015b; Kerch et al., 2018), while the shear-wave velocity $\left(V_{s}\right)$ is considered a proxy for the shear stiffness.

Seismic estimations from synthetic modeling of the PRFs (P receiver functions) of $V_{p}$ and $V_{s}$ in Antarctic and Greenland ice sheets reveal a strong decrease of $\sim 25 \%$ of $V_{s}$ in the lower third part of the ice sheet, while $V_{p}$ remains approximately constant (Wittlinger \& Farra, 2012). The zone with a drastic $V_{s}$ decrease corresponds to the basal "radio-echo free zone", where largescale disturbances (Drews et al., 2009; Bons et al., 2016) and strong CPOs are found (Eisen et al., 2007; Weikusat et al., 2017). According to Wittlinger \& Farra (2015), the low $V_{s}$ may be due to the presence of water resulting from pre-melting at grain joints and/or melting of chemical solutions buried in ice. The presence of low percentages of melt $(<5 \%)$ in ice masses has also been suggested based on variations in radio-wave velocities (Macheret et al., 1993; Murray et al., 2000).

Experimental studies performed on rocks, as for example in water saturated and cracked rocks (e.g., O’Connell \& Budiansky, 1974) or granitic rocks including silicate melt and water (e.g., Watanabe, 1993), shown that seismic velocities depend on both the CPO and the water content. No systematic experimental studies have been carried out using temperate ice, and theoretical models based on the effective medium approach (Endres et al., 2009) are used to predict the amount of water inclusions and/or veins within solid ice. To the authors knowledge, no studies of the effect of water in polar ice on seismic velocities during ice-sheet flow (or deformation) have been performed so far.

We investigate the variation of seismic velocities during deformation of temperate ice by means of microdynamic numerical simulations. Deformation is assumed to be simple shear, as that is the dominant flow regime in lower parts of ice sheets, because there ice flows parallel to the bedrock (Montagnat et al., 2014). Temperate ice is simulated as a two-phase non-linear viscous aggregate constituted by a solid phase (ice polycrystals) and a liquid phase (water) in two dimensions. The viscoplastic full-field numerical approach (VPFFT) (Lebensohn, 2001; Lebensohn et al., 2008) is used to calculate the mechanical response of the two-phase aggregate, in which intracrystalline deformation is assumed to be accommodated by dislocation glide. These simulations couple viscoplastic deformation with dynamic recrystallization processes, in order to simulate deep ice-sheet conditions (characterized by high temperature and simple shear deformation).

The equilibrium distribution of melt in an aggregate is controlled by the dihedral angle $(\omega)$ (Rosenberg, 2001). However, the shape of solid grains and melt pockets can be constantly modified by recrystallization processes (Walte et al., 2003). To include this effect, viscoplastic deformation is coupled with dynamic recrystallization $(D R X)$ processes, including grain boundary migration, intracrystalline recovery and polygonization (Steinbach et al., 2016; Llorens et al., 2017), all driven by the reduction of surface and strain energies. Therefore, the numerical approach allows the simulation of the evolution of the CPO and water pocket distribution during ductile deformation of a polycrystalline aggregate. From these results, we calculate the evolution of $V_{p}$ and $V_{s}$ as a function of orientation during deformation. We simulate aggregates with different water fractions, in order to understand their effect on the resulting microstructures of the deforming ice and water aggregate. 


\section{Methods, experimental setup and postprocessing}

The microstructural evolution of ice aggregates including a water phase is simulated using the numerical simulation platform ELLE (http://www.elle.ws; Jessell et al., 2001; Bons et al., 2008; Piazolo et al., 2019). The numerical approach is based on the coupling of a full-field viscoplastic code using the Fast Fourier Transform algorithm (VPFFT; Lebensohn, 2001; Lebensohn et al., 2008; Lebensohn \& Rollett, 2020) and different ELLE modules that simulate $D R X$. The VPFFT formulation provides a solution of the micromechanical problem by finding a strain rate and stress field that minimize the average local work rate under the compatibility and equilibrium constraints. The estimated geometrically necessary dislocation (GND) densities and deformation-induced lattice rotations are calculated integrating in time the velocity gradient fields provided by VPFFT. Both are used to simulate dynamic recrystallization by grain boundary migration $(G B M)$, intracrystalline recovery and polygonization. $G B M$ is simulated using a front-tracking approach based on a modification of the algorithm by Becker et al. (2008) (also see Roessiger et al., 2014, Steinbach et al., 2016 and Llorens et al., 2016a). The GBM module reproduces the motion or displacement of high-angle grain boundaries (HAGB) (Karato, 2012) driven by the reduction of the stored strain energy and grain boundary energy. The displacement of the boundaries is carried out following the direction of maximum energy reduction and depending on the grain-boundary mobility, in a way that the work done equals the change in the local energy state (see Becker et al., 2008). Dislocation densities are set to zero in regions swept by grain boundaries. Steinbach et al. (2016) provides a detailed description of the two-phase $G B M$ module. Recovery reduces the intra-granular stored energy in a deformed crystal, simulating annihilation of dislocations and their rearrangement into low-angle subgrains (Urai et al. 1986; Borthwick et al, 2014). Llorens et al. (2016a) and Gomez-Rivas et al. (2017) provide a complete description of the intra-crystalline recovery module. The polygonization module simulates the nucleation of new high-angle grain boundaries (HAGB) in highly deformed grains. An extended description of the polygonization module can be found in Llorens et al. (2017). The most relevant studies performed in ELLE for the presented contribution are the microstructural evolution of ice including air bubbles in static (Roessiger et al., 2014) and dynamic conditions (Steinbach et al., 2016), the effect of dynamic recrystallization on the microstructural evolution of polycrystalline ice (Llorens et al., 2016a, 2016b, 2017; Steinbach et al., 2016) and rocksalt (Gomez-Rivas et al. 2017) aggregates, as well as partially molten rocks (Llorens et al., 2019).

The data structure is defined by a set of polygons (called flynns) in a two-dimensional section of the modelled microstructure of ice polycrystals and water pockets. Flynns are defined by boundary nodes (bnodes) which are connected by straight boundary segments (see Fig. 1b in Llorens et a., 2019). Three types of boundaries are present in the modelled material: (i) ice-ice, (ii) ice-water and (iii) water-water. The magnitude of the mobility of the ice-water boundary is much less constrained, for which reason we consider here that its mobility is equal to the mobility of an ice-ice boundary $\left(0.023 \mathrm{~m}^{4} \mathrm{~J}^{-1} \mathrm{~s}^{-1}\right.$; Nasello et al., 2005). To achieve the relatively low dihedral angle $(\omega)$ observed for ice-water equilibrium of $\omega=30^{\circ}$ (Ketcham \& Hobbs, 1969), we assume a surface energy for ice-water boundaries of $0.034 \mathrm{Jm}^{-2}$ (see eq. 2 in Llorens et al., 2019) and for ice-ice boundaries of $0.065 \mathrm{Jm}^{-2}$ (Ketcham and Hobbs, 1969). Artificial waterwater boundaries do occur in the models in order to maintain the polygon topology but have no physical meaning and therefore no effect on the microstructural evolution. For this reason, the water-water boundaries are not displayed in the figures. At the considered representative volume element of the modelled microstructure the surface forces strongly dominate over the gravity 
force, and therefore no gravity is included in this simulation approach (Piazolo et al., 2019 and references therein).

The microstructure is discretized in a regular mesh of $256 \times 256$ unconnected nodes (unodes or Fourier points), resulting in a unit cell defined by 65,536 nodes. Each unode represents a small area or crystallite used for storing the crystal orientation, strain rate, local stress and dislocation density (see Fig. 1c in Llorens et al., 2019). Crystal orientations are defined by the three Euler angles following the Bunge convention. Note that the water phase in the VPFFT numerical setup was also treated as an effectively isotropic non-linear viscous material, with a stiffness close to zero, so that its properties approximate those of a noncrystalline liquid (see Llorens et al., 2019). An increment of the spatial resolution of the unodes provides more degrees of freedom to adjust local gradients, improving the resolution of intracrystalline heterogeneities. A higher resolution produces similar grain and subgrain sizes, but with better defined boundaries (see Fig. 12 in Llorens et al., 2016a). However, more importantly, the increment of resolution does not affect on the intensity and orientation of the developed CPO, resulting in a prediction of a very similar seismic velocities. A comparison between simulations discretized in 128, 256 and 512 unodes would shift the absolute values of predicted $V_{p}$ by $-0.26 \%$ to $+0.1 \%$ and $V_{s}$ by $-0.05 \%$ to $+0.05 \%$

In order to link the development of a CPO with the arising seismic anisotropy, simulations start with a random lattice orientation of ice polycrystals, representing a bulk isotropic material. The M-index, which indicates the strength of the c-axis orientation density distribution, is less than 0.007 for the three simulations presented, where zero indicates a random lattice orientation and one a single crystal orientation (Skemer et al., 2005).

At the equilibrium melting point water in polycrystalline ice can be located in films at the interface between two grains, in tubes at the intersection of three grains or in tetrahedral pockets at the intersection of four grains, depending on the assumed dihedral angle (Hobbs \& Ketcham, 1974). At the assumed $\omega \approx 30^{\circ}$ water would be located in triangular tubes at three-grain intersections (von Bargen \& Waff, 1986; Walte et al., 2003). The equivalent of such tubes in our two-dimensional models with low water fractions of $\phi=0 \%, 5 \%$ and $15 \%$ are concave triangular water pockets on grain triple junctions (Fig.1a). The water percentages used are higher than the percentages estimated in nature ( $<5 \%$ ) (Benjumea et al., 2003; Navarro et al., 2005; Murray et al., 2007). This is to correct for stereological effects by which high- $\phi$ simulations in 2D correspond to lower- $\phi$ cases in 3D. Unfortunately, a simple conversion cannot be provided owing to stereological complications that arise when water pockets become stretched and distorted. A similar stereological issue will be encountered again below in the calculation of seismic velocities.

In our simulations the strain rate $\dot{\varepsilon}_{i j}$ at each unode position $(x)$ in the mesh corresponds to the sum of the product between the shear strain rates $\left(\dot{\gamma}^{s}\right)$ and the Schmid tensor $\left(m_{i j}^{S}\right)$ of the three defined slip systems $(s)$ : pyramidal, prismatic and basal,

$$
\dot{\varepsilon}_{i j}(x)=\sum_{s=1}^{3} m_{i j}^{s}(x) \dot{\gamma}^{s}(x)
$$

The shear strain rate is related to the deviatoric stress $\left(\sigma_{i j}^{\prime}\right)$ by

$$
\dot{\gamma}^{s}(x)=\dot{\gamma}_{0}\left(\frac{\left|m_{i j}^{s}(x) \sigma_{i j}^{\prime}(x)\right|}{\tau^{s}(x)}\right)^{n} \times \operatorname{sign}\left(m_{i j}^{s}(x) \sigma_{i j}^{\prime}(x)\right)
$$


where $\tau^{S}$ is the critical resolved shear stress (CRSS) required for the activation of the slip system, $\dot{\gamma_{0}}$ is a reference strain-rate and $n$ is the stress exponent. The anisotropy $(A)$ of every phase is defined by the ratio between the CRSS of the non basal $v s$ basal slip system:

$$
A=\frac{\tau_{\text {non basal }}}{\tau_{\text {basal }}}
$$

For the solid phase (ice) $A$ was set to 60 and a value of stress exponent $n=3$ was chosen for all slip systems (see Llorens et al., 2017). For the water phase the CRSS was defined 100 times lower than that assumed for the ice basal slip system.

Each process in ELLE is applied sequentially in a loop that represents a small time increment $(\Delta t)$ (Bons et al., 2008). A dextral shear strain increment $(\gamma)$ of 0.02 parallel to the horizontal shear plane is applied first. Each simulation step comprised 10 recrystallization steps per deformation step and equalled a total time step of $3.15 \times 10^{9} \mathrm{~s}$, resulting in a shear strain rate of $\sim 6 \times 10^{-12} \mathrm{~s}^{-1}$. Each simulation reached a finite shear strain of up to 8. This operator splitting approach avoids issues with the order in which the recrystallization processes are applied and increases the stability of the numerical solution (see Llorens et al., 2016a, 2016b, 2017 and 2019). As the size of the model is $10 \times 10 \mathrm{~cm}$, the simulations performed are located in the transition between the deformation- and the recrystallization-controlled regime (see Llorens et al., 2019). This value of strain rate is coherent with those estimated for the base of the GRIP, NGRIP and NEEM ice cores, where the shear strain rate is in order of $10^{-12} \mathrm{~s}^{-1}$ (Montagnat et al., 2014). A variation in the DRX rate (i.e., strain rate) is not considered in this contribution. Using the ELLE-VPFFT simulation approach Llorens et al. (2019) provides a description of the effect of DRX on the microstructure of partially molten rocks and the corresponding strain rates.

As both VPFFT and ELLE use periodic boundaries, the model is repositioned into the square grid after every time step of dextral shear strain, facilitating the visualization of the microstructure at very high strain (Jessell et al., 2009; Llorens et al., 2013a; 2013b). We use the three Euler angles stored at every unode of the model for the representation of the crystallographic preferred orientation, shown as pole figures and EBSD maps and the calculation of the M-index. These data are plotted using the texture analysis software MTEX (https://mtextoolbox.github.io; Mainprice et al., 2015) from the orientation distribution function (ODF), which represents the volume fraction of unodes with a certain orientation.

Seismic wave velocities (P-wave and faster S-wave) and their anisotropy are calculated from single-crystal stiffness and the three Euler angles using the AEH-EBSD Analysis Toolbox (https://umaine.edu/mecheng/vel/software/esp_toolbox/; Naus-Thijseen, 2011; Vel et al., 2016). The Asymptotic Expansion Homogenization (AEH) method allows the effect of the two-phase distribution on the seismic waves to be investigated. This method discretizes the model in a finite element (FE) mesh and explicitly accounts for the microstructural contribution of the different phases for the bulk elastic stiffness and average density of the aggregate, computing the elastic interactions between different phases. In this method the seismic velocities are calculated from single crystal stiffness, density and the three Euler angles stored at every unode of the model that represent the CPO. Previous studies have predicted the seismic velocities from sample-measured CPO in mantle and crustal rocks (Erdman et al., 2013; Llana-Funez et al., 2009; Zhong et al., 2014). In Zhong et al. (2014) the predicted seismic velocities are also compared with laboratory measurements, testifying that the CPO is the dominant factor controlling seismic anisotropy. 
We use the stiffness for a single ice crystal $\left(\rho=0.920 \mathrm{~g} / \mathrm{cm}^{3}\right)$ at $-30^{\circ} \mathrm{C}$ and $-1^{\circ} \mathrm{C}(\rho=0.916$ $\mathrm{g} / \mathrm{cm}^{3}$ ) according to Dantl (1968), where the elastic moduli of ice in a complete range of temperatures from $-140^{\circ} \mathrm{C}$ to $0^{\circ} \mathrm{C}$ are calculated. Using the elastic constants reported by Gammon et al. (1983), Bass et al. (1957) and Green and McKinnon (1956) would shift the absolute values of predicted $V_{p}$ by $-2.6 \%$ to $+0.9 \%$ and $V_{s}$ by $+0.5 \%$ to $3 \%$, all considered along the maximum c-axis direction. However, more importantly, the anisotropy and trends in $V_{p}$ and $V_{s}$ values with increasing strain are not affected.

For the prediction of the seismic wave velocities from the water-ice aggregate, we assume that the water phase is an isotropic elastic solid with Poisson's ratio very close to 0.5 (i.e., 0.4999) and a density of $\rho=0.998 \mathrm{~g} / \mathrm{cm}^{3}$. Note that with this assumption the water phase is almost incompressible with a shear modulus $10^{-4}$ times the bulk modulus of water $(K=2.3 \mathrm{GPa}$; Yoon \& Cowin, 2009).

\section{Results}

\subsection{Microstructure and CPO evolution}

The models presented here were run with three different water fractions of $\phi=0 \%, 5 \%$ and $15 \%$ ( $\gamma=0$ in Fig. 1). By comparing them we can observe the microstructural and crystal orientation evolution as a function of the water fraction. For a purely solid aggregate $(\phi=0 \%)$ deformation is localized in high-strain bands of small grains almost parallel to the shear plane, separated by low-strain areas of elongated, larger grains obliquely oriented to the shear plane. A grain size reduction due to polygonization is observed in the high-strain bands (see $\phi=0 \%$ at $\gamma$ $=8$ in Fig. 1). The presence of water decreases the formation of high-strain bands, because water accommodates part of the deformation. At low water percentage $(\phi=5 \%)$ bands with elongated grains and grain size reduction are still recognizable (Fig. 1). However, when the water percentage is higher $(\phi=15 \%)$ high-strain bands are not observed in the grain boundary network (see $\phi=15 \%$ at $\gamma=8$ in Fig. 1).

The intensity of DRX applied in the simulations allows water pockets to retain their concave shape, which in turn results in merging of the initial water pockets and forming larger pockets. The formation of large water pockets is clearly observed when the water fraction is high $(\phi=15 \%)$ (Fig. 1). 
(a) $\phi=0 \%$
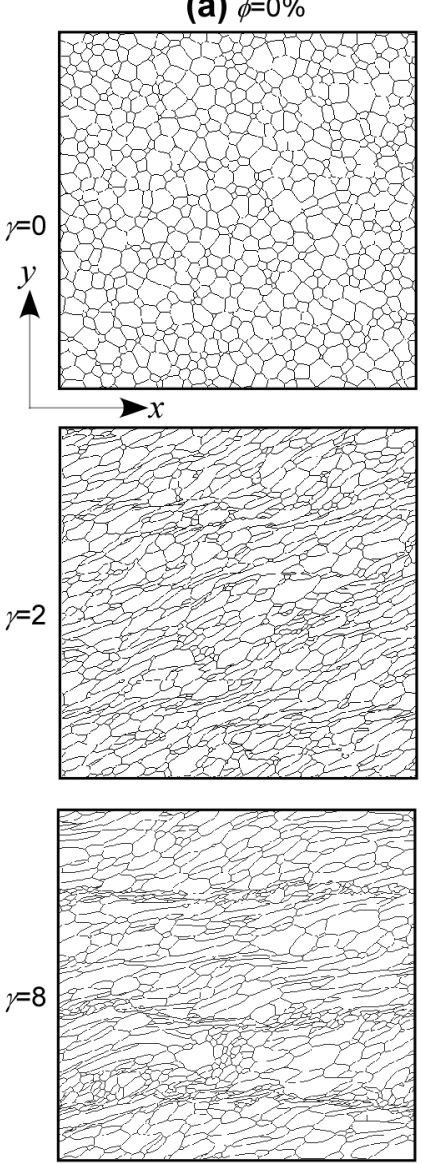

$V_{p}(\mathrm{~km} / \mathrm{s})$

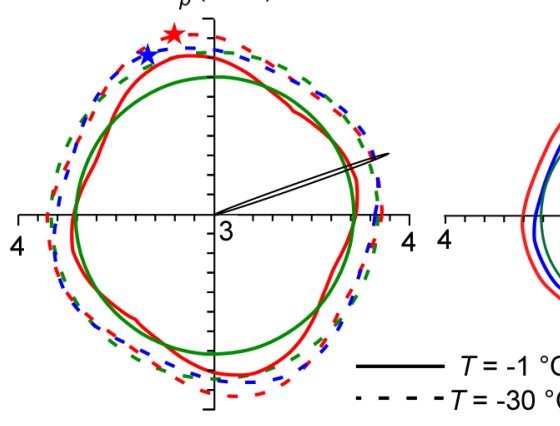

(b) $\phi=5 \%$
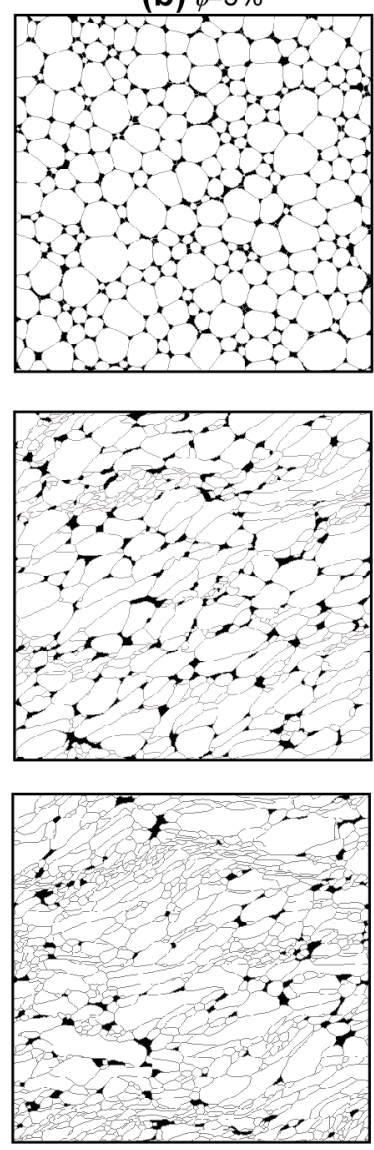

$V_{p}(\mathrm{~km} / \mathrm{s})$ (c) $\phi=15 \%$
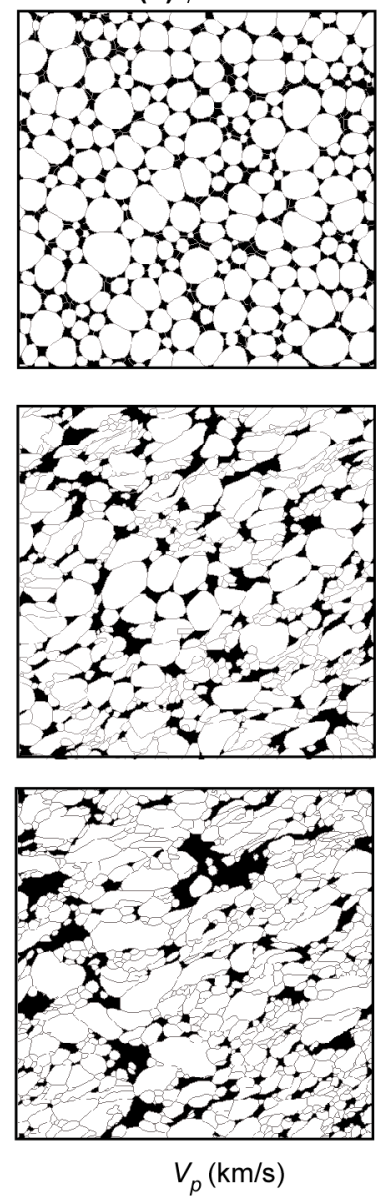
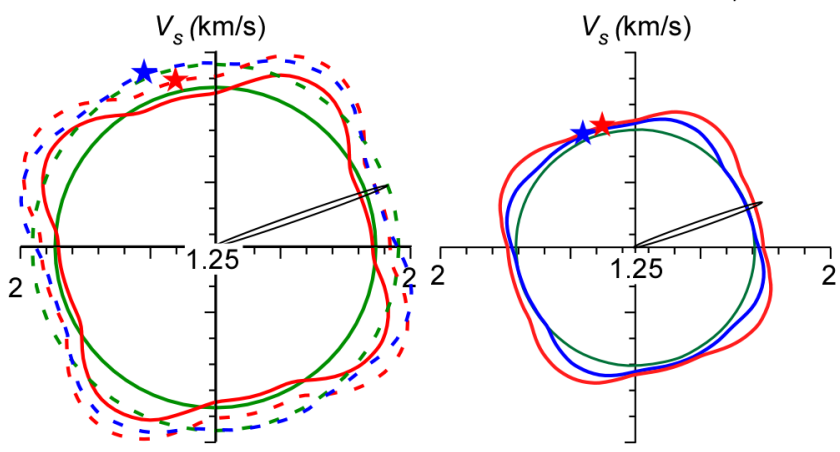

44
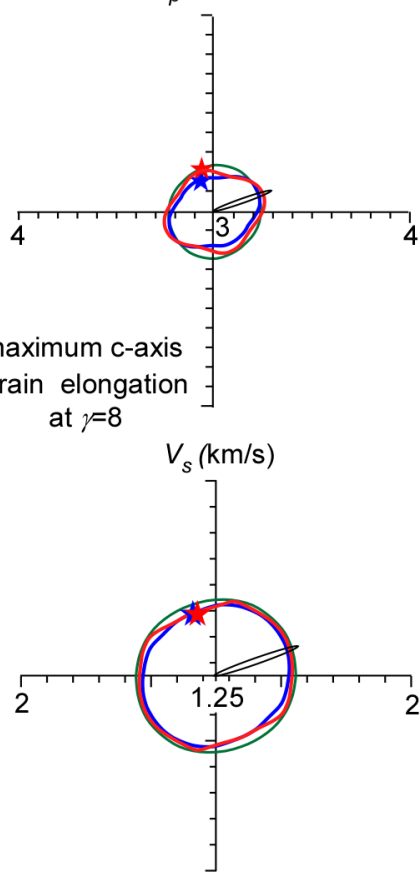

Figure 1. Grain boundary networks of simulations with the three percentages of water $\phi=0 \%$ (a), $5 \%$ (b) and $15 \%$ (c) at the different stages of deformation $(\gamma=0,2$ and 8$)$. Water inclusions are 
shown in black and grain boundaries in light grey. Corresponding distribution of the $V_{p}$ and $V_{s}$ in the simulated 2D plane $(x y)$ at $\gamma=0,2$ and 8 , for each simulation. The maximum c-axis density at different $\gamma$ are indicated in the graph. Grain elongation at the final stage $(\gamma=8)$ is shown in the graph. A temperature of $-1^{\circ} \mathrm{C}$ (solid line) is considered for the elastic moduli of the partially molten ice simulations (b and c). Notice that the influence of temperature on $V_{p}$ and $V_{s}$ predictions is shown in (a), where a comparison between predictions for the pure ice simulation ( $\phi=0 \%$ ) assuming a temperature of $-1{ }^{\circ} \mathrm{C}$ and $-30^{\circ} \mathrm{C}$ is shown.

Inverse pole figure maps and pole figures of lattice orientations during deformation are shown in Figure 2. Regardless of the water percentage, all simulations evolve from a random fabric to a c-axis maximum density distribution approximately perpendicular to the shear plane. For all simulations, the $c$-axis maximum is well developed by a shear strain of $\gamma=2$, as shown by the pattern of $c$-axes on the pole figures in Fig. $2 b$. The strength of the maximum c-axis density distribution increases from $\gamma=2$ to $\gamma=8$ (Fig. 2c-d) as shown by the misorientation index (Mindex; Skemer et al., 2005) (Fig. 4c). However, when water is present the developed c-axis maximum is less intense than for the pure ice simulation (Fig. 2 Columns II and III), followed by a weaker alignment of the $a$-axes and $m$-planes. This observed weakening of the ice CPO increases with water content, consistent with the water phase carrying a higher proportion of the applied strain as its volume fraction increases.

\subsection{Calculation of seismic velocity anisotropy with the AEH method}

We use the Asymptotic Expansion Homogenization (AEH) method with Voight homogeneization at the finite element level to obtain theoretical predictions of P-wave $\left(V_{p}\right)$ and S-wave $\left(V_{S}\right)$ velocities and their anisotropy for the deformed microstructures at different steps of shear strain, up to $\gamma=8$ (Fig. 1). The corresponding seismic anisotropy is calculated as $\mathrm{AV}=[(\mathrm{Vmax}-\mathrm{Vmin}) /((\mathrm{Vmax}+\mathrm{Vmin}) / 2)] \times 100$. In order to take into account the temperature sensitivity of elastic waves in ice (Kohnen, 1974), we assume a temperature of $-30^{\circ} \mathrm{C}$ for the pure ice aggregate, and $-1{ }^{\circ} \mathrm{C}$ for the aggregates containing ice and water $(\phi=5 \%$ and $15 \%)$. For these AEH predictions, the elastic constants of ice at these temperatures are taken from Dantl (1968).

For a purely solid aggregate ( $\phi=0 \%)$ the direction of maximum value of $V_{p}$ is always aligned with the maximum c-axis, which is oriented at low angle $\alpha\left(<20^{\circ}\right)$ with respect to the vertical or $y$ direction (see column a in Fig. 1). A second maximum of $V_{p}$ is located at $90^{\circ}$ with respect to the orientation of the maximum c-axis. With progressive deformation the strength of the maximum c-axis density distribution increases and, consequently, $V_{p}$ is increased (Fig. 1). At the same time, this strengthening reduces $V_{s}$ in the orientation of the maximum c-axis (Fig. 1). Anellipticity phenomena are observed, where the maximum $V_{s}$ is located at $45^{\circ}$ with respect to the maximum $V_{p}$ (Sayers, 2018).

When a low percentage of water is present $(\phi=5 \%)$ the maximum $V_{p}$ and minimum $V_{s}$ directions are parallel to the maximum c-axis orientation (see columns b and c in Fig. 1), similar to the purely solid case. However, as the developed maximum c-axis is less intense, both the $V_{p}$ and $V_{s}$ are lower than in the purely solid case. At high percentage of water $(\phi=15 \%)$ both $V_{p}$ and $V_{s}$ are considerably reduced. The maximum $V_{p}$ and minimum $V_{s}$ are not aligned with the maximum c-axis, but follow the orientation of the grain elongation (see red line for the $\phi=15 \%$ simulation in Fig. 1). In this case the $V_{p}$ and $V_{s}$ orientation cannot be used as a proxy to predict the maximum c-axis. 
Due to geothermal heat flux, ice is generally warmer in the lower parts than in the upper parts of ice sheets. To show the effect of temperature on the purely solid aggregate $(\phi=0 \%)$, Column a in Figure 1 includes the seismic velocities predicted considering a temperature of $-1^{\circ} \mathrm{C}$ and $-30^{\circ} \mathrm{C}$.

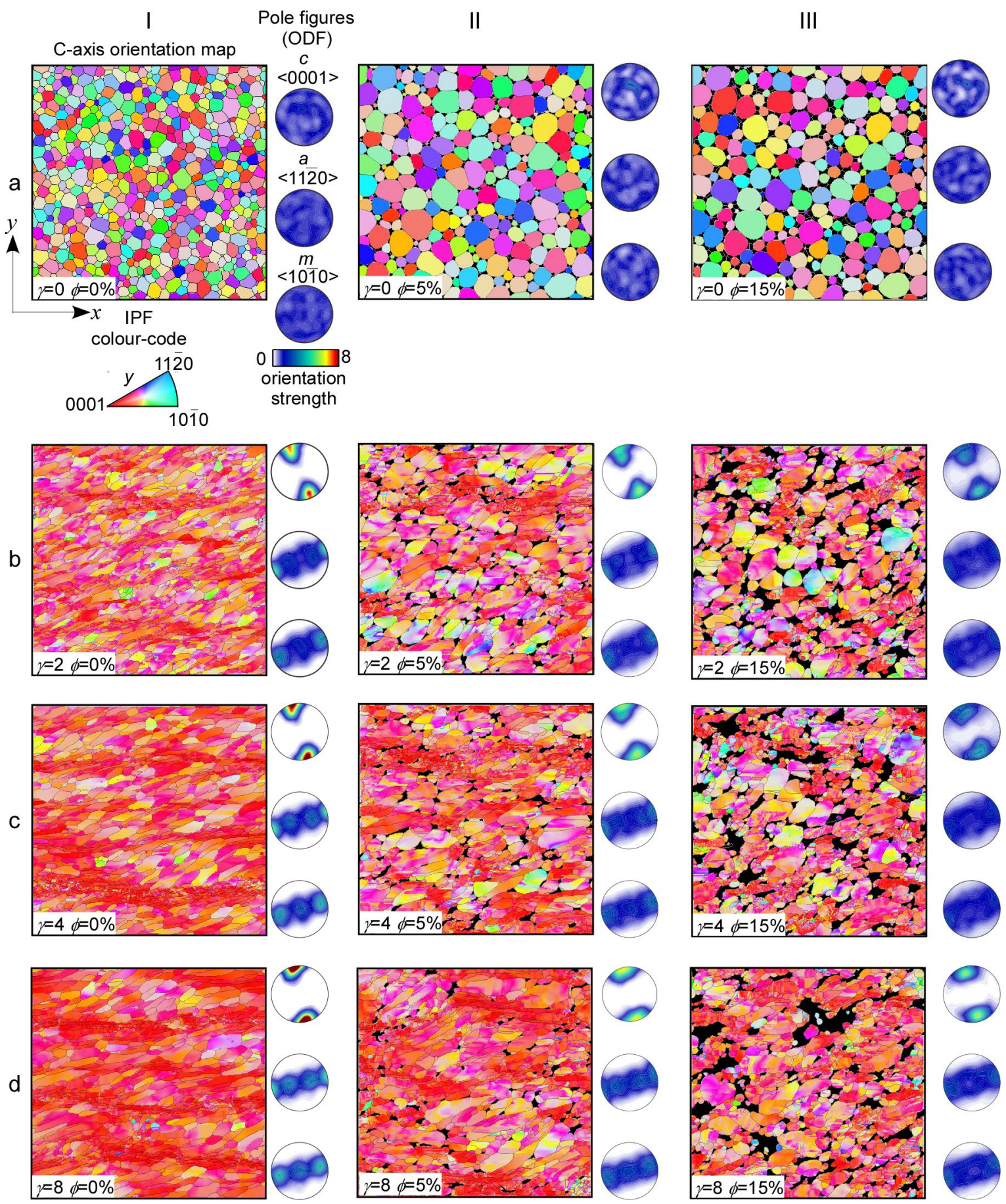

Figure 2. (a) C-axis orientation map of the undeformed starting ice microstructure. The inverse pole figure (IPF) color-code indicates the lattice orientation with respect to the $y$-direction. The 
corresponding pole figure projections indicate the orientation density (ODF) of the c-axis $(<0001>)$, a-axis $(<11<20>)$ and $\mathrm{m}$ - axis $(<10-10>)$. Evolution of the simulations at a shear strain of (b) $\gamma=2$, (c) $\gamma=4$ and (d) $\gamma=8$. Columns I, II and III show the three percentages of water $(\phi)$ considered in this study, $0 \%, 5 \%$ and $15 \%$, initially nucleated at triple grain junctions. Water inclusions are shown in black and grain boundaries in light grey.
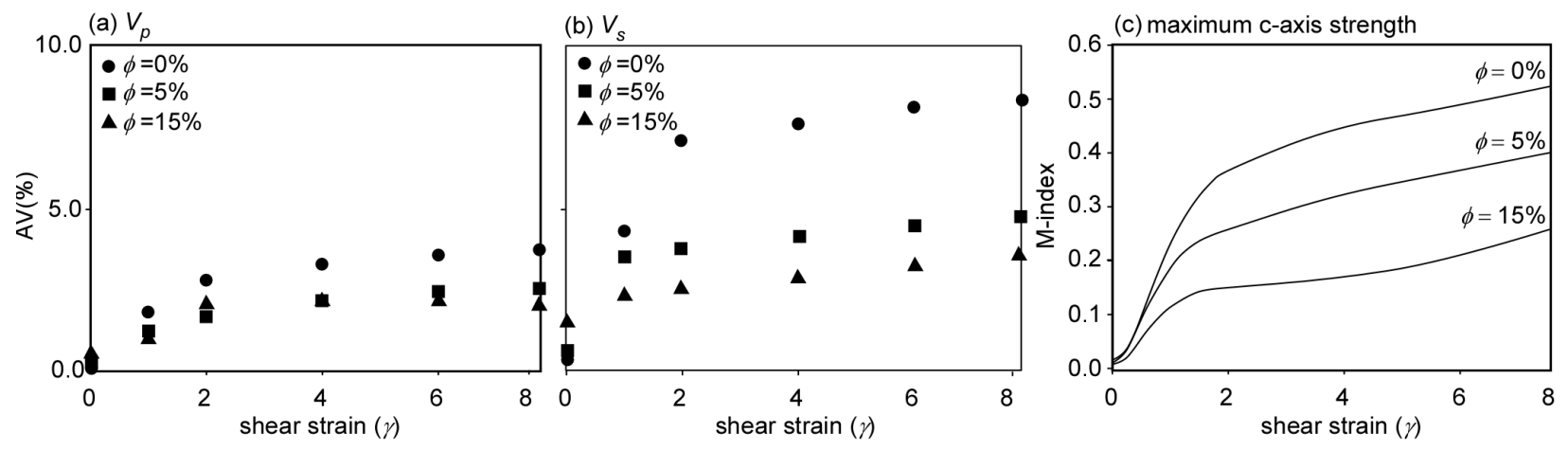

Figure 3. Magnitude (\%) of (a) $V_{p}$ and (b) $V_{s}$ anisotropy, calculated as $\mathrm{A} V=[(\operatorname{Vmax}$ $V \min ) /((\max +V \min ) / 2)] \mathrm{x} 100$, for all simulations performed. (c) Evolution of the maximum caxis orientation density distribution strength shown as the misorientation index (M-index; Skemer et al., 2005), where zero represents a random fabric and one a single crystal fabric. A temperature of $-30^{\circ} \mathrm{C}$ is considered for the elastic moduli (Dantl, 1968) of the pure ice simulation $(\phi=0 \%)$, while a temperature of $-1{ }^{\circ} \mathrm{C}$ is considered for the partially molten ice simulations $(\phi=5 \%$ and $15 \%)$.

For all simulations the $V_{p}$ anisotropy increases rapidly up to shear strain of $\gamma=2$, and then it increases moderately (Fig. 3a). A similar evolution is predicted for the $V_{s}$ anisotropy, where the highest increment occurs up to $\gamma=2$ (Fig. 3b). As expected, higher anisotropies are observed in $\mathrm{S}$-wave velocities. The seismic anisotropy results from the preferred orientation of ice crystal caxes towards the vertical direction, as observed from the evolution of the strength of the maximum c-axis orientation density revealed by the M-index (see $\phi=0 \%$ in Fig. 3c). When water in present, the anisotropy of both $V_{p}$ and $V_{s}$ is reduced (see $\phi=5 \%$ and $15 \%$ in Fig. 3a-b) compared with the pure ice case, as the developed maximum c-axis orientation density is less intense (see M-index in Fig. 3c).

\section{Discussion}

Near the surface of ice sheets polycrystalline ice is assumed to be isotropic, since the single ice crystals are approximately randomly oriented. The anisotropy of ice polycrystals due to crystal reorientation increases with depth, with a strong maximum c-axis developing towards the deepest parts of ice sheets (Faria et al., 2014). In our simulations, under simple shear boundary conditions, the crystal orientation evolves from a random distribution of c-axes to a strong maximum c-axis oriented almost perpendicular to the shear plane, as described by shear experiments (Bouchez \& Duval, 1982), and as observed in ice-core crystal-orientation analyses (e.g., Hudleston, 1977; Faria et al., 2014; Montagnat et al., 2014; Weikusat et al,. 2017).

A large number of previous studies have tried to link the microstructures of polar ice with their geophysical signature, aiming to use the seismic velocity anisotropy as a proxy to predict 
maximum c-axis orientations that formed during ice flow (Kerch et al., 2018). Relationships between microstructures and seismic velocity anisotropy have been applied to the study of natural ice core samples in Antarctica (Kohnen \& Gow, 1979; Anandakrishnan \& Alley, 1994; Gusmeroli et al., 2012; Kluskiewicz et al., 2017), active-source (Navarro et al., 2005; Picotti et al., 2015; Vélez et al., 2016) and passive-source (Smith et al., 2015; 2017) seismic field measurements, prediction using modelling techniques (Diez \& Eisen, 2015a; 2015b) and ice ductile creep experiments (Vaughan et al., 2017). The simulations presented here also reveal a direct link between maximum c-axis development and the orientations of $V_{p}$ and $V_{s}$. When a purely solid ice aggregate, or that with a low percentage of water is considered $(\phi=5 \%)$, the evolution from an initially random distribution of c-axes to a maximum coincides with the maximum $V_{p}$ and minimum $V_{s}$ orientation, as predicted by experiments (Vaughan et al., 2017) and as measured in natural ice core samples (Kohnen \& Gow, 1979; Kohnen \& Betley, 1977). However, when the percentage of water is higher $(\phi=15 \%)$ the orientation of $V_{p}$ and $V_{s}$ cannot be used as a proxy to unravel crystal preferred orientations.

Seismic anisotropy mainly develops during the first strain increment, up to $\gamma \approx 2$, after which anisotropy increases much more slowly. This would imply that a remnant fabric and its corresponding seismic anisotropy from a previous stress regime would not remain if it is affected by a change in ice flow lasting for an amount of strain greater than the equivalent of $\gamma \approx 2$, contrary to the assumption in Smith et al. (2017). The effect of a change in a stress regime on ice microstructure has been previously described using ice deformation experiments, where a preexisting c-axis orientation is completely reoriented at a strain of $20 \%$ of axial vertical compression (Craw et al., 2018).

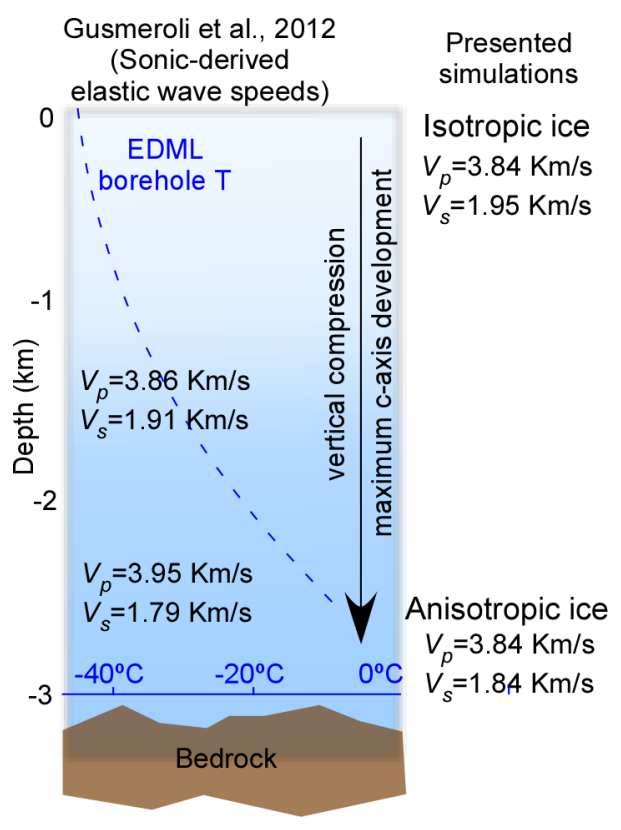

Figure 4. Idealized polar ice sheet, comparing seismic velocities measured at the EPICA Dome $\mathrm{C}$ borehole (Gusmeroli et al., 2012) and those obtained in the presented simulations, all considered along the maximum c-axis direction. In upper layers, ice is considered isotropic, as it presents a random distribution of c-axis orientation. In depth temperature increases due to 
geothermal heat flux, shown by the EDML borehole temperature (Weikusat et al., 2017), and ice becomes anisotropic because it develops a maximum c-axis orientation parallel to the vertical compression.

In our simulations that represent near-surface ice-sheet conditions (i.e., characterized by purely solid bulk isotropic ice and assuming a low temperature of $-30^{\circ} \mathrm{C}$ ) the predicted $V_{p}$ and $V_{s}$ in the direction of the developed maximum c-axis orientation are $3.84 \mathrm{~km} / \mathrm{s}$ and $1.95 \mathrm{~km} / \mathrm{s}$, respectively (Fig.4 and Table 1a). Due to the geothermal flux, ice temperature increases with depth, while at the same time a strong c-axis maximum develops due to ice flow in non-coaxial conditions (i.e., bedrock-parallel flow). The predicted $V_{p}$ and $V_{s}$ in simulations representing these conditions are $3.84 \mathrm{~km} / \mathrm{s}$ and $1.84 \mathrm{~km} / \mathrm{s}$, respectively. Temperature causes a reduction of both $V_{p}$ and $V_{s}$, being the latter slightly less reduced (Kohnen \& Gow, 1979; Vaughan et al., 2017), while ice flow increases the $V_{p}$ and reduces the $V_{s}$ along the maximum c-axis direction. Therefore, the combination of the effects of temperature and ice flow results in an approximately constant standard value of $V_{p}$ in the whole ice sheet but in a $5 \%$ reduction of $V_{s}$ values in its deep parts (Fig. 4 and Table 1a). These simulation results are coherent with in-situ wave speed measurements performed at the EPICA Dome C (Gusmeroli et al., 2012). In this comparison both thin-section-derived and sonic-derived elastic wave speeds at the Dome $\mathrm{C}$ show a decrease of $V_{s}$ between $5 \%$ and $8 \%$ in depth.

Following seismic estimations from synthetic modeling of the PRFs (P receiver functions) from surveys in Antarctica and Greenland, polar ice sheets can be divided into an upper layer with seismic velocities similar to the standard ice values, measured in the vertical or close to the vertical direction (i.e., isotropic ice values; Gagnon et al., 1988), and a lower layer with standard $V_{p}$ values but with $V_{s} 17 \%$ to $30 \%$ lower than those measured in the upper part (Wittlinger and Farra, 2012). However, according to our results the temperature dependence of ice elastic parameters (Dantl, 1968), together with the increment of $V_{p}$ and decrease of $V_{s}$ along the maximum c-axis direction due the bulk ice anisotropy development (Gagnon et al., 1988), cannot explain the estimated strong decrease of $25 \%$ in the $V_{s}$ in the lower part of ice sheets.

Wittlinger \& Farra (2015) proposed the presence of unfrozen liquids along the ice grain boundaries as the cause of the low shear-wave velocities found in the lower ice layer. But, as our simulations indicate, the presence of water reduces both $V_{p}$ and $V_{s}$. Even if melting occurs in a microstructure with a strong crystal preferred orientation, $V_{p}$ would get proportionally reduced by the presence of water (see Table 1a). The reduction of the compressional wave velocity $\left(V_{p}\right)$ is attributed to the difference between the bulk modulus of ice and the bulk modulus or water, which is assumed one order of magnitude lower in this contribution. To find a significant decrease in $V_{s}$ a presence of $\phi>10 \%$ water would be required. However, in that case $V_{p}$ would also be strongly decreased (see Table 1a).

The strong reduction of both $V_{p}$ and $V_{s}$ due to the presence of melt or water in granite rocks has been previously described by Watanabe (1993), where the $V_{p} / V_{s}$ ratio remains similar to the pure solid value up to $15 \%$ of water content, when it increases moderately. However, $V_{p}$ $/ V_{s}$ increases with increasing the melt fraction. This effect is observable at very low melt percentages (see Fig.2 in Watanabe, 1993). In our simulations we observe a moderate and proportional increment of the $V_{p} / V_{s}$ ratio with increasing the water fraction (see Table 1a).

The simulations presented in this contribution are located at the transition between the deformation- and the recrystallization-controlled regimes (see Llorens et al., 2019). At this 
transition, water pockets can merge but still form isolated water pools, because $G B M$ can counteract changes in the pocket shapes to maintain the equilibrium dihedral angle. According to Endres et al. (2009), our simulations are equivalent to undrained conditions, as possibility of out flow by gravity is not considered. In our simulations, all the water is located in grain triple junctions and not in veins (see condition $\Phi=0.0$ in Fig. 1 in Endres et al., 2009). With progressive deformation water pockets merge to form larger pockets, but not water chains. According to this model for undrained conditions $V_{p}$ remains constant regardless the water content. For undrained conditions the bulk modulus of the water-and-ice aggregate must tend to have the bulk modulus of ice. If we assume this condition, and therefore that water located in ice has the same bulk modulus as ice at $-1^{\circ} \mathrm{C}$ (Parameswaran, 1987), $V_{s}$ gets significantly reduced proportionally to the presence of water, while $V_{p}$ is only slightly reduced (Table $1 \mathrm{~b}$ ). With water fractions ranging from $5 \%$ to $10 \% V_{p}$ would be $\sim 3.83 \mathrm{~km} / \mathrm{s}$, similar to the purely solid isotropic ice simulation (standard), but $V_{s}$ would be reduced by up to $15 \%$ (Table $1 \mathrm{~b}$ ).

\section{Table 1}

Predicted $V_{p}$ and $V_{s}(\mathrm{Km} / \mathrm{s})$ along the maximum c-axis direction depending on the polycrystal anisotropy, temperature and percentage of water. Water is nucleated at triple junctions after the development of a crystal preferred orientation. For the predictions presented in (a) the bulk modulus of water (K=2.3 GPa; Yoon \& Cowin, 2009) is assumed for the water phase, as well as a shear modulus $10^{-4}$ times lower than the bulk modulus and a Poisson ratio of 0.4999. For the predictions presented in (b) the bulk modulus of ice is assumed for both the solid ice and water phases, implying that water is compressed. The bulk modulus has been calculated from the ice Young's modulus at $-1{ }^{\circ} \mathrm{C}$ (Parameswaran, 1987) and assuming a Poisson ratio of 0.4999. The shear modulus is kept $10^{-4}$ times lower than the bulk modulus.

\begin{tabular}{|c|c|c|c|c|c|c|c|}
\hline \multirow[t]{2}{*}{ Ice conditions } & \multirow[t]{2}{*}{$\mathrm{T}^{\mathrm{o}}$} & \multicolumn{3}{|c|}{ (a) } & \multicolumn{3}{|c|}{ (b) } \\
\hline & & $V_{p}$ & $V_{S}$ & $V_{p} / V_{s}$ & $V_{p}$ & $V_{S}$ & $V_{p} / V_{s}$ \\
\hline $\begin{array}{l}\text { Purely-solid isotropic ice } \\
\text { (standard) }\end{array}$ & $-30^{\circ} \mathrm{C}$ & 3.84 & 1.95 & 1.97 & - & - & - \\
\hline Purely-solid anisotropic ice & $-1^{\circ} \mathrm{C}$ & 3.84 & 1.84 & 2.07 & - & - & - \\
\hline Anisotropic ice $+5 \%$ water & $-1^{\circ} \mathrm{C}$ & 3.70 & 1.77 & 2.10 & 3.84 & 1.77 & 2.17 \\
\hline Anisotropic ice $+10 \%$ water & $-1^{\circ} \mathrm{C}$ & 3.51 & 1.67 & 2.10 & 3.83 & 1.66 & 2.31 \\
\hline Anisotropic ice $+15 \%$ water & $-1^{\circ} \mathrm{C}$ & 3.30 & 1.53 & 2.16 & 3.80 & 1.54 & 2.46 \\
\hline
\end{tabular}

At undrained conditions water is necessarily located in isolated pockets and not forming water networks. This condition also implies an elevated fluid pressure at ice-sheet basal parts. This condition would be in accordance with the observations of temperate ice glaciers, where basal water pressure reaches $96 \%$ of the ice overburden pressure when the temperature is near the freezing point (Iken \& Bindschadler, 1986; Jansson, 1995; Sugiyama \& Gudmundsson, 2004; Sugiyama, et al., 2011). The presence of water at these conditions would not favor sliding between ice grains. That would correspond to a thermomechanical regime of a warm-based ice sheet but with a thin temperate layer, where most of the deformation is internal and can be described by a standard power law (Krabbendam, 2016). According to these results, and even assuming that water is at elevated pressure conditions, the observed strong decrease of $25 \%$ of $V_{s}$ in the lower part of ice sheets (Wittlinger \& Farra, 2015) would imply an unrealistic proportion of water in the system, probably higher than $15 \%$. 
It should be borne in mind that, due to stereological effects, our high- $\phi$ simulations in 2D correspond to lower- $\phi$ in 3D cases (von Bargen \& Walf, 1986). Therefore, a direct comparison with water percentages in rock experiments or in nature cannot be directly done, where the same effect would occur at lower percentages of water (Llorens et al., 2019). But this is not expected to change the joint reduction of both $V_{p}$ and $V_{s}$ with increasing water fraction.

However, if we consider that the dynamic conditions in the lower part of ice sheets correspond to the deformation-dominated regime, the effective dihedral angle will be $\omega \approx 0^{\circ}$, because recrystallization is too slow to counteract the shearing of water pockets (Llorens et al., 2019). The initial shape and location of water pockets is not important, because pockets get stretched continuously (de Meer et al., 2005; Koehn et al., 2006). As indicated in de Meer et al. (2005), melt films located on grain boundaries will modify and even overprint the CPOdependent orientation and magnitude seismic anisotropy.

\section{Conclusions}

This study presents a series of full-field simple shear numerical simulations of dynamic recrystallization of two-phase non-linear viscous materials that represent temperate ice. The analysis of the resulting ice microstructures and the seismic wave velocities have led to the following main conclusions:

1. In the absence of or at low percentage of water seismic velocities can be used as a continuous proxy for the evolution of c-axis orientation in deforming ice. However, when the percentage of water is high $(\phi=15 \%)$ the direction of $V_{p}$ and $V_{s}$ cannot be used as a proxy to unravel crystal preferred orientations.

2. The presence of water reduces both $V_{p}$ and $V_{s}$ proportionally. The reduction of the compressional wave velocity $\left(V_{p}\right)$ is attributed to the difference between the bulk modulus of ice and the bulk modulus of water, which is assumed one order of magnitude lower than that of ice in this contribution.

3. If water resides at high pressure, and thus assuming that it has the bulk modulus of ice, we find a remarkable decrease of $V_{s}$ while $V_{p}$ remains close to the value for water-free ice. These results suggest that the decrease in $V_{s}$ observed in the base of ice sheets could be explained by the presence of basal water at elevated pressure. This water would reside in isolated and unconnected pockets at grain triple junctions and thus would not form melt bands. Such distribution would correspond to a flow regime where recrystallization dominates over deformation.

4. In systems where deformation dominates over recrystallization water pockets get continuously stretched, allowing water films to be located at grain boundaries. This configuration would modify and even overprint the maximum c-axis-dependent orientation and the magnitude of seismic anisotropy.

\section{Acknowledgments}

MGL acknowledges a Juan de la Cierva-Formación (FJCI-2015-2417) and a Juan de la CiervaIncorporación (IJC2018-036826-I) fellowships, both funded by the Spanish Ministry of Science, Innovation and Universities. EGR acknowledges the support of the Ramón y Cajal fellowship 
funded by the Spanish Ministry of Science, Innovation and Universities Spanish Ministry of Science, Innovation and Universities (RYC2018-026335-I).

\section{Data Availability Statement}

The codes for the simulation of viscoplastic deformation and dynamic recrystallization are open source and available at http://www.elle.ws. The software for the prediction of seismic velocities from crystal orientation datasets is freely accessible at

https://umaine.edu/mecheng/vel/software/esp toolbox/. The data generated and employed in this study are available at the corresponding Zenodo data repository (Llorens et al., 2020; https://doi.org/10.5281/zenodo.4028550). The data sets contain (i) the output files with the crystal orientation and phase data of each simulation presented in the article (for time steps 50, $100,200,300$ and 400), and (ii) a code to plot the crystallographic orientation density function (ODF) using the open-source code MTEX.

\section{References}

Anandakrishnan, S. \& Alley, R.B. (1994). Ice Stream C, Antarctica, sticky spots detected by microearthquake monitoring. Annals of Glaciology, 20, 183-186.

https://doi.org/10.3189/1994AoG20-1-183-186

Azuma, N. \& Goto-Azuma, K. (1996). An anisotropic flow law for ice-sheet ice and its implications. Annals of Glaciology, 23, 202-208. https://doi.org/10.3189/S0260305500013458

Barnes, P., Tabor, D., \& Walker, J. C. F. (1971). The friction and creep of polycrystalline ice. Proceedings of the Royal Society London A., 324, 127-155.

https://doi.org/10.1098/rspa.1971.0132

Bass, R., D. Rossberg, and G. Ziegler (1957), Die elastichen konstanten des eises, Z. Phys. A, 149, 199-203

Becker, J.K., Bons, P.D., \& Jessell, M.W. (2008). A new front-tracking method to model anisotropic grain and phase boundary motion in rocks. Computers \& Geosciences, 34, 201-212. https://doi.org/10.1016/j.cageo.2007.03.013

Benjumea, B., Macheret, Y.Y., Navarro, F.J., \& Teixidó, T. (2003). Estimation of water content in a temperate glacier from radar and seismic sounding data. Annals of Glaciology, 37, 317-324. https://doi.org/10.3189/172756403781815924

Bons, P.D., Koehn, D., \& Jessell, M.W. (2008). Microdynamic Simulation. Lecture Notes in Earth Sciences 106, Springer, Berlin. 405 pp.

Bons, P.D., Jansen, D., Mundel, F., Bauer, C.C., Binder, T., Eisen, O., Jessell, M.W., Llorens, M.G., Steinbach, F., Steinhage, D. \& Weikusat, I. (2016). Converging flow and anisotropy cause large-scale folding in Greenland's ice sheet. Nature Communications, 7(1), 1-6. https://doi.org/10.1038/ncomms11427

Bons, P.D., Kleiner, T., Llorens, M.G., Prior, D.J., Sachau, T., Weikusat, I. \& Jansen, D. (2018). Greenland Ice Sheet: Higher nonlinearity of ice flow significantly reduces estimated basal motion. Geophysical Research Letters, 45(13), 6542-6548.

https://doi.org/10.1029/2018GL078356 
Borthwick, V.E., Piazolo, S., Evans, L., Griera, A. \& Bons, P.D. (2014). What happens to deformed rocks after deformation? A refined model for recovery based on numerical simulations. Geological Society, London, Special Publications, 394(1), 215-234. https://doi.org/10.1144/SP394.11

Bouchez, J.L., \& Duval, P. (1982). The fabric of polycrystalline ice deformed in simple shear: experiments in torsion, natural deformation and geometrical interpretation. Texture, Stress, and Microstructure, 5(3), 171-190.

Budd, W. F., \& T. H. Jacka. (1989). A review of ice rheology for ice sheet modelling. Cold Regions Science and Technology, 16(2), 107-144. https://doi.org/10.1016/0165-232X(89)900141

Castelnau, O., Duval, P., Lebensohn, R.A., \& Canova, G.R. (1996). Viscoplastic modeling of texture development in polycrystalline ice with a self-consistent approach: Comparison with bound estimates. Journal of Geophysical Research: Solid Earth, 101(B6), 13851-13868, https://doi.org/10.1029/96JB00412

Craw, L., Qi, C., Prior, D.J., Goldsby, D.L., \& Kim, D. (2018). Mechanics and microstructure of deformed natural anisotropic ice. Journal of Structural Geology, 115, 152-166.

https://doi.org/10.1016/j.jsg.2018.07.014

Cuffey, K.M., \& Paterson, W.S.B. (2010). The physics of glaciers. Academic Press.

Dahl-Jensen, D., Mosegaard, K., Gundestrup, N., Clow, G.D., Johnsen, S.J., Hansen, A.W. \& Balling, N. (1998). Past temperatures directly from the Greenland ice sheet. Science, 282(5387), 268-271. 10.1126/science.282.5387.268

Dantl, G. (1968). Die elastischen Moduln von Eis-Einkristallen. Physik der kondensierten Materie, 7(5), 390-397.

de Meer, S., Spiers, C.J. \& Nakashima, S. (2005). Structure and diffusive properties of fluidfilled grain boundaries: An in-situ study using infrared (micro) spectroscopy. Earth and Planetary Science Letters, 232(3-4), 403-414. https://doi.org/10.1016/j.epsl.2004.12.030

Diez, A., \& Eisen, O. (2015a). Seismic wave propagation in anisotropic ice-Part 1: Elasticity tensor and derived quantities from ice-core properties. The Cryosphere, 9(1), 367-384.

doi:10.5194/tc-9-367-2015

Diez, A., Eisen, O., Hofstede, C., Lambrecht, A., Mayer, C., Miller, H., Steinhage, D., Binder, T., \& Weikusat, I. (2015b). Seismic wave propagation in anisotropic ice-Part 2: Effects of crystal anisotropy in geophysical data. The Cryosphere, 9(1), 385-398. doi:10.5194/tc-9-385-2015

Durand, G., Svensson, A., Persson, A., Gagliardini, O., Gillet-Chaulet, F., Sjolte, J., Montagnat, M., \& Dahl-Jensen, D., (2009). Evolution of the texture along the EPICA Dome C ice core. Low Temperature Science, 68(Supplement), 91-105.

Duval, P. (1977). The role of the water content on the creep rate of polycrystalline ice. IAHS Publ. 118 (Symposium at Grenoble 1975 - Isotopes and Impurities in Snow and Ice), 29-33.

Duval, P., Ashby, M.F., \& Anderman, I. (1983). Rate-controlling processes in the creep of polycrystalline ice. The Journal of Physical Chemistry, 87(21), 4066-4074. 
Drews, R., Eisen, O., Weikusat, I., Kipfstuhl, S., Lambrecht, A., Steinhage, D., Wilhelms, F., \& Miller, H. (2009). Layer disturbances and the radio-echo free zone in ice sheets. The Cryosphere, 3, 195-203. https://doi.org/10.5194/tc-3-195-2009

Eisen, O., Hamann, I., Kipfstuhl, S., Steinhage, D., \& Wilhelms, F. (2007). Direct evidence for continuous radar reflector originating from changes in crystal-orientation fabric. The Cryosphere, 1, 1-10, doi: https://doi.org/10.5194/tc-1-1-2007.

Endres, A.L., Murray, T., Booth, A.D., \& West, L.J. (2009). A new framework for estimating englacial water content and pore geometry using combined radar and seismic wave velocities. Geophysical Research Letters, 36(4). https://doi.org/10.1029/2008GL036876

EPICA community members (2004). Nature, 429, 623-628. 10.1038/nature02599

Erdman, M. E., B. R. Hacker, G. Zandt, and G. Seward (2013), Seismic anisotropy of the crust: Electron-backscatter diffraction measurements from the Basin and Range, Geophys. J. Int., 195(2), 1211-1229. https://doi.org/10.1093/gji/ggt287

Faria, S.H., Kipfstuhl, S., Azuma, N., Freitag, J., Hamann, I., Murshed, M.M., \& Kuhs, W.F. (2009). The multiscale structure of Antarctica. Part I: inland ice. Low Temp. Sci., 68, 39-59.

Faria, S.H., Weikusat, I., \& Azuma, N. (2014). The microstructure of polar ice. Part I: Highlights from ice core research. Journal of Structural Geology, 61, 2-20.

https://doi.org/10.1016/j.jsg.2013.09.010

Gagnon, R.E., Kiefte, H., Clouter, M.J., \& Whalley, E. (1988). Pressure dependence of the elastic constants of ice Ih to 2.8 kbar by Brillouin spectroscopy. The Journal of Chemical Physics, 89(8), 4522-4528. ttps://doi.org/10.1063/1.454792

Gammon, P.H., Kiefte, H., Clouter, M.J., \& Denner, W.W. (1983). Elastic constants of artificial and natural ice samples by Brillouin spectroscopy. Journal of Glaciology, 29(103), 433-460. https://doi.org/10.3189/S0022143000030355

Gillet-Chaulet, F., Gagliardini, O., Meyssonnier, J., Montagnat, M., \& Castelnau, O. (2005). A user-friendly anisotropic flow law for ice-sheet modeling. Journal of Glaciology, 51(172), 3-14. https://doi.org/10.3189/172756505781829584

Glen, J.W. (1955). The creep of polycrystalline ice. Proceedings of the Royal Society of London. Series A. Mathematical and Physical Sciences, 228(1175), 519-538.

https://doi.org/10.1098/rspa.1955.0066

Goldsby, D.L., \& Kohlstedt, D.L. (2001). Superplastic deformation of ice: Experimental observations. Journal of Geophysical Research: Solid Earth, 106(B6), 11017-11030.

https://doi.org/10.1029/2000JB900336

Gomez-Rivas, E., Griera, A., Llorens, M.-G., Bons, P. D., Lebensohn, R. A., \& Piazolo, S. (2017). Subgrain Rotation Recrystallization During Shearing: Insights from Full-Field Numerical Simulations of Halite Polycrystals. Journal of Geophysical Research: Solid Earth, 122(11), 8810-8827. https://doi.org/10.1002/2017JB014508

Gow, A.J., \& Williamson, T. (1976). Rheological implications of the internal structure and crystal fabrics of the West Antarctic ice sheet as revealed by deep core drilling at Byrd Station. Geological Society of America Bulletin, 87(12), 1665-1677. https://doi.org/10.1130/00167606(1976)87<1665:RIOTIS >2.0.CO;2 
Gow, A.J., \& Engelhardt, H. (2000). Preliminary analysis of ice cores from Siple Dome, West Antarctica. In: Hondoh, T. (Ed.), Physics of Ice Core Records, Hokkaido University Press, 6382.

Green Jr, R.E. and Mackinnon, L., 1956. Determination of the elastic constants of ice single crystals by an ultrasonic pulse method. The Journal of the Acoustical Society of America, 28(6), pp.1292-1292. https://doi.org/10.1121/1.1908626

Gudlaugsson, E., Humbert, A., Kleiner, T., Kohler, J., \& Andreassen, K. (2016). The influence of a model subglacial lake on ice dynamics and internal layering. The Cryosphere, 10, 751-760, doi: https://doi.org/10.5194/tc-10-751-2016

Gusmeroli, A., Pettit, E.C., Kennedy, J.H., \& Ritz, C. (2012). The crystal fabric of ice from fullwaveform borehole sonic logging. Journal of Geophysical Research: Earth Surface, 117(F3). https://doi.org/10.1029/2012JF002343

Hanna, E., Pattyn, F., Navarro, F., Favier, V., Goelzer, H., van den Broeke, M.R., Vizcaino, M., Whitehouse, P.L., Ritz, C., Bulthuis, K., \& Smith, B. (2019). Mass balance of the ice sheets and glaciers-progress since AR5 and challenges. Earth-Science Reviews, p.102976.

https://doi.org/10.1016/j.earscirev.2019.102976

Hobbs, P.V., \& Ketcham, W.M. (1974). Physics of ice. Clarendon, Oxford.

Hooke, R.L., \& Hudleston, P.J. (1978). Origin of foliation in glaciers. Journal of Glaciology, 20(83), 285-299. https://doi.org/10.3189/S0022143000013848

Hudleston, P.J. (1977). Progressive deformation and development of fabric across zones of shear in glacial ice. In Energetics of geological processes. In: Saxena S.K., Bhattacharji S., Annersten H., Stephansson O. (eds) Energetics of Geological Processes. Springer, Berlin, Heidelberg, pp. 121-150. https://doi.org/10.1007/978-3-642-86574-9_7

Hudleston, P.J. (2015). Structures and fabrics in glacial ice: a review. Journal of Structural Geology, 81, 1-27. https://doi.org/10.1016/j.jsg.2015.09.003

Iken, A., \& Bindschadler, R.A. (1986). Combined measurements of subglacial water pressure and surface velocity of Findelengletscher, Switzerland: conclusions about drainage system and sliding mechanism. Journal of Glaciology, 32(110), 101-119.

https://doi.org/10.3189/S0022143000006936

IPCC. IPCC Special Report on the Ocean and Cryosphere in a Changing Climate (IPCC, 2019).

Jansson, P. (1995). Water pressure and basal sliding on Storglaciären, northern Sweden. Journal of Glaciology, 41(138), 232-240. https://doi.org/10.3189/S0022143000016130

Jessell, M.W., Bons, P., Evans, L., Barr, T., \& Stüwe, K. (2001). Elle: the numerical simulation of metamorphic and deformation microstructures. Computers \& Geosciences, 27, 17-30. https://doi.org/10.1016/S0098-3004(00)00061-3

Jessell, M.W., Bons, P.D., Griera, A., Evans, L.A., \& Wilson, C.J.L. (2009). A tale of two viscosities. Journal of Structural Geology, 31, 719-736. https://doi.org/10.1016/j.jsg.2009.04.010

Kamb, B. (1972). Experimental recrystallisation of ice under stress. Washington DC American Geophysical Union Geophysical Monograph Series, 16, 211-241.

https://doi.org/10.1029/GM016p0211 
Karato, S.I. (2012). Deformation of earth materials: an introduction to the rheology of solid Earth. Cambridge University Press.

Kerch, J., Diez, A., Weikusat, I., \& Eisen, O. (2018). Deriving micro-to macro-scale seismic velocities from ice-core c axis orientations. The Cryosphere, 12(5), 1715-1734. 10.5194/tc-12$1715-2018$

Ketcham, W.M., \& Hobbs, P.V. (1969). An experimental determination of the surface energies of ice. Philosophical Magazine, 19(162), 1161-1173.

https://doi.org/10.1080/14786436908228641

Kluskiewicz, D., Waddington, E.D., Anandakrishnan, S., Voigt, D.E., Matsuoka, K., \& McCarthy, M.P. (2017). Sonic methods for measuring crystal orientation fabric in ice, and results from the West Antarctic ice sheet (WAIS) Divide. Journal of Glaciology, 63(240), 603-617. https://doi.org/10.1017/jog.2017.20

Koehn, D., Malthe-Sørenssen, A., \& Passchier, C.W. (2006). The structure of reactive grainboundaries under stress containing confined fluids. Chemical Geology, 230(3-4), 207-219. https://doi.org/10.1016/j.chemgeo.2006.02.026

Kohnen, H. (1974). The temperature dependence of seismic waves in ice. Journal of Glaciology, 13(67), 144-147. https://doi.org/10.3189/S0022143000023467

Kohnen, H., \& Bentley, C. (1977). Ultrasonic measurements on ice cores from Ross Ice Shelf, Antarctica, drill hole. Antarctic Journal US, 12(4), 148-150.

Kohnen, H., \& Gow, A.J. (1979). Ultrasonic velocity investigations of crystal anisotropy in deep ice cores from Antarctica. Journal of Geophysical Research: Oceans, 84(C8), 4865-4874. https://doi.org/10.1029/JC084iC08p04865

Kopp, R.E., DeConto, R.M., Bader, D.A., Hay, C.C., Horton, R.M., Kulp, S., Oppenheimer, M., Pollard, D., \& Strauss, B.H. (2017). Evolving understanding of Antarctic ice-sheet physics and ambiguity in probabilistic sea-level projections. Earth's Future, 5(12), 1217-1233. https://doi.org/10.1002/2017EF000663

Krabbendam, M. (2016). Sliding of temperate basal ice on a rough, hard bed: creep mechanisms, pressure melting, and implications for ice streaming. The Cryosphere, 10(5), 1915-1932. https://doi.org/10.5194/tc-10-1915-2016

Kuiper, E.J.N., de Bresser, J.H., Drury, M.R., Eichler, J., Pennock, G.M., \& Weikusat, I. (2020). Using a composite flow law to model deformation in the NEEM deep ice core, Greenland: Part 2 the role of grain size and premelting on ice deformation at high homologous temperature. The Cryosphere, in press. https://doi.org/10.5194/tc-2018-275

Lebensohn, R.A. (2001). N-site modelling of a 3D viscoplastic polycrystal using fast Fourier transform. Acta Materialia, 49(14), 2723-2737. https://doi.org/10.1016/S1359-6454(01)00172-0

Lebensohn, R.A., Brenner, R., Castelnau, O., \& Rollett, A.D. (2008). Orientation image-based micromechanical modelling of subgrain texture evolution in polycrystalline copper. Acta Materialia, 56(15), 3914-3926. doi: 10.1016/j.actamat.2008.04.016. https://doi.org/10.1016/j.actamat.2008.04.016 
Lebensohn, R.A., \& Rollett, A.D. (2020). Spectral methods for full-field micromechanical modelling of polycrystalline materials. Computational Materials Science, 173, 109336. https://doi.org/10.1016/j.commatsci.2019.109336

Lliboutry, L., \& Duval, P. (1985). Various isotropic and anisotropic ices found in glaciers and polar ice caps and their corresponding rheologies. Annales Geophysicae, 3(2), 207-224. Doi: http://10.1016/0148-9062(85)90267-0

Llana-Funez, S., D. Brown, R. Carbonell, J. Alvarez-Marron, and M. Salisbury (2009), Seismic anisotropy of upper mantle-lower continental crust rocks in Cabo Ortegal (NW Spain) from crystallographic preferred orientation (CPO) patterns, Trabajos de Geol., 29, 432-436.

Llorens, M.-G., Bons, P.D., Griera, A., \& Gomez-Rivas, E. (2013a). When do folds unfold during progressive shearing? Geology, 41, 563-566. https://doi.org/10.1130/G33973.1

Llorens, M.-G., Bons, P.D., Griera, A., \& Gomez-Rivas, E. (2013b). Single layer folding in simple shear. Journal of Structural Geology, 50, 209-220.

https://doi.org/10.1016/j.jsg.2012.04.002

Llorens, M. G., Griera, A., Bons, P. D., Roessiger, J., Lebensohn, R., Evans, L., \& Weikusat, I. (2016a). Dynamic recrystallisation of ice aggregates during co-axial viscoplastic deformation: a numerical approach. Journal of Glaciology, 62, 359-377. https://doi.org/10.1017/jog.2016.28

Llorens, M. G., Griera, A., Bons, P. D., Lebensohn, R. A., Evans, L. A., Jansen, D., \& Weikusat, I. (2016b). Full field predictions of ice dynamic recrystallisation under simple shear conditions. Earth and Planetary Science Letters, 450, 233-242. https://doi.org/10.1016/j.epsl.2016.06.045

Llorens, M.G., Griera, A., Steinbach, F., Bons, P.D., Gomez-Rivas, E., Jansen, D., Roessiger, J., Lebensohn, R.A., \& Weikusat, I. (2017). Dynamic recrystallization during deformation of polycrystalline ice: insights from numerical simulations. Philosophical Transactions of the Royal Society el London A, 375 20150346. https://doi.org/10.1098/rsta.2015.0346

Llorens, M.G., Gomez-Rivas, E., Ganzhorn, A.C., Griera, A., Steinbach, F., Roessiger, J., Labrousse, L., Walte, N.P., Weikusat, I., \& Bons, P.D. (2019). The effect of dynamic recrystallisation on the rheology and microstructures of partially molten rocks. Journal of Structural Geology, 118, 224-235. https://doi.org/10.1016/j.jsg.2018.10.013

Llorens, M.-G., Griera, A., Bons, P.D., Gomez-Rivas, E., Weikusat, I., Prior, D., Kerch., J. \& Lebensohn, R.A. (2020). Full-field numerical simulations of temperate ice viscoplastic deformation and dynamic recrystallization [Data set]. Journal of Geophysical Research: Earth Surface. Zenodo. http://doi.org/10.5281/zenodo.4028550

MacGregor, J.A., Fahnestock, M.A., Catania, G.A., Aschwanden, A., Clow, G.D., Colgan, W.T., Gogineni, S.P., Morlighem, M., Nowicki, S.M., Paden, J.D., \& Price, S.F. (2016). A synthesis of the basal thermal state of the Greenland Ice Sheet. Journal of Geophysical Research: Earth Surface, 121(7), 1328-1350. https://doi.org/10.1002/2015JF003803

Macheret, Y.Y., Moskalevsky, M.Y., \& Vasilenko, E.V. (1993). Velocity of radio waves in glaciers as an indicator of their hydrothermal state, structure and regime. Journal of Glaciology, 39(132), 373-384. https://doi.org/10.3189/S0022143000016038

Mainprice, D., Bachmann, F., Hielscher, R., \& Schaeben, H. (2015). Descriptive tools for the analysis of texture projects with large datasets using MTEX: strength, symmetry and 
components. Geological Society, London, Special Publications, 409(1), 251-271.

https://doi.org/10.1144/SP409.8

Montagnat, M., Azuma, N., Dahl-Jensen, D., Eichler, J., Fujita, S., Gillet-Chaulet, F., Kipfstuhl, S., Samyn, D., Svensson, A., \& Weikusat, I. (2014). Fabric along the NEEM ice core, Greenland, and its comparison with GRIP and NGRIP ice cores. The Cryosphere, 8, 1129-1138, doi: https://doi.org/10.5194/tc-8-1129-2014

Murray, T., Stuart, G.W., Fry, M., Gamble, N.H., \& Crabtree, M.D. (2000). Englacial water distribution in a temperate glacier from surface and borehole radar velocity analysis. Journal of Glaciology, 46(154), 389-398. https://doi.org/10.3189/172756500781833188

Murray, T., Booth, A., \& Rippin, D.M. (2007). Water-content of glacier-ice: limitations on estimates from velocity analysis of surface ground-penetrating radar surveys. Journal of Environmental \& Engineering Geophysics, 12(1), 87-99. http://dx.doi.org/10.2113/JEEG12.1.87

Naus-Thijssen, F.M., Goupee, A.J., Vel, S.S., \& Johnson, S.E. (2011). The influence of microstructure on seismic wave speed anisotropy in the crust: Computational analysis of quartzmuscovite rocks. Geophysical Journal International, 185(2), 609-621. https://doi.org/10.1111/j.1365-246X.2011.04978.x

Nasello, O.B., Di Prinzio, C.L., \& Guzmán, P.G. (2005). Temperature dependence of "pure" ice grain boundary mobility. Acta Materialia, 53(18), 4863-4869.

https://doi.org/10.1016/j.actamat.2005.06.022

Navarro, F.J., Macheret, Y.Y., \& Benjumea, B. (2005). Application of radar and seismic methods for the investigation of temperate glaciers. Journal of Applied Geophysics, 57(3), 193211. https://doi.org/10.1016/j.jappgeo.2004.11.002

NEEM community members. (2013). Eemian interglacial reconstructed from a Greenland folded ice core. Nature, 493, 489-494, doi:10.1038/nature11789. https://doi.org/10.1038/nature11789

O'Connell, R.J., \& Budiansky, B. (1974). Seismic velocities in dry and saturated cracked solids. Journal of Geophysical Research, 79(35), 5412-5426. https://doi.org/10.1029/JB079i035p05412

Parameswaran, V.R. (1987). Orientation dependence of elastic constants for ice. Defence Science Journal, 37(3), 367-375.

Piazolo, S., Bons, P.D., Griera, A., Llorens, M.G., Gomez-Rivas, E., Koehn, D., Wheeler, J., Gardner, R., Godinho, J.R., Evans, L., \& Lebensohn, R.A. (2019). A review of numerical modelling of the dynamics of microstructural development in rocks and ice: Past, present and future. Journal of Structural Geology, 125, 111-123. https://doi.org/10.1016/j.jsg.2018.05.025

Picotti, S., Vuan, A., Carcione, J.M., Horgan, H.J., \& Anandakrishnan, S. (2015). Anisotropy and crystalline fabric of Whillans Ice Stream (West Antarctica) inferred from multicomponent seismic data. Journal of Geophysical Research: Solid Earth, 120(6), 4237-4262.

https://doi.org/10.1002/2014JB011591

Price, P.B., Nagornov, O.V., Bay, R., Chirkin, D., He, Y., Miocinovic, P., Richards, A., Woschnagg, K., Koci, B., \& Zagorodnov, V. (2002). Temperature profile for glacial ice at the South Pole: Implications for life in a nearby subglacial lake. PNAS, 99 (12), 7844-7847. https://doi.org/10.1073/pnas.082238999 
Rignot, E. (2006). Changes in ice dynamics and mass balance of the Antarctic ice sheet. Philosophical Transactions of the Royal Society A: Mathematical, Physical and Engineering Sciences, 364(1844), 1637-1655. https://doi.org/10.1098/rsta.2006.1793

Rignot, E., \& Mouginot, J. (2012). Ice flow in Greenland for the International Polar Year 20082009. Geophysical Research Letters, 39, L11501. https://doi.org/10.1029/2012GL051634

Roessiger, J., Bons, P.D., \& Faria, S.H. (2014). Influence of bubbles on grain growth in ice. Journal of Structural Geology. Journal of Structural Geology, 61, 123-132.

https://doi.org/10.1016/j.jsg.2012.11.003

Rosenberg, C.L. (2001). Deformation of partially molten granite: a review and comparison of experimental and natural case studies. International Journal of Earth Sciences, 90(1), 60-76. https://doi.org/10.1007/s005310000164

Sayers, C.M. (2018). Elastic anisotropy of polycrystalline ice with transversely isotropic and orthotropic symmetry. Geophysical Journal International, 215(1), 155-164. https://doi.org/10.1093/gji/ggy274

Skemer, P., Katayama, I., Jiang, Z., \& Karato, S.I. (2005). The misorientation index: Development of a new method for calculating the strength of lattice-preferred orientation. Tectonophysics, 411(1-4), 157-167. https://doi.org/10.1016/j.tecto.2005.08.023

Smith, E.C., Baird, A.F., Kendall, J.M., Martín, C., White, R.S., Brisbourne, A.M., \& Smith, A.M. (2017). Ice fabric in an Antarctic ice stream interpreted from seismic anisotropy. Geophysical Research Letters, 44(8), 3710-3718. https://doi.org/10.1002/2016GL072093

Smith, E.C., Smith, A.M., White, R.S., Brisbourne, A.M., \& Pritchard, H.D. (2015). Mapping the ice-bed interface characteristics of Rutford Ice Stream, West Antarctica, using microseismicity. Journal of Geophysical Research: Earth Surface, 120(9), 1881-1894. https://doi.org/10.1002/2015JF003587

Souchez, R., Lemmens, M., Tison, J.L., Lorrain, R., \& Janssens, L. (1993). Reconstruction of basal boundary conditions at the Greenland Ice Sheet margin from gas composition in the ice. Earth and Planetary Science Letters, 118(1-4), 327-333. https://doi.org/10.1016/0012821X(93)90176-A

Steinbach, F., Bons, P. D., Griera, A., Jansen, D., Llorens, M. G., Roessiger, J., \& Weikusat, I. (2016). Strain localization and dynamic recrystallization in the ice-air aggregate: a numerical study. The Cryosphere, 10(6), 3071. 10.5194/tc-10-3071-2016

Sugiyama, S., \& Gudmundsson, G.H. (2004). Short-term variations in glacier flow controlled by subglacial water pressure at Lauteraargletscher, Bernese Alps, Switzerland. Journal of Glaciology, 50(170), 353-362. https://doi.org/10.3189/172756504781829846

Sugiyama, S., Skvarca, P., Naito, N., Enomoto, H., Tsutaki, S., Tone, K., Marinsek, S., \& Aniya, M. (2011). Ice speed of a calving glacier modulated by small fluctuations in basal water pressure. Nature Geoscience, 4(9), 597-600. https://doi.org/10.1038/ngeo1218

Thorsteinsson, T., Kipfstuhl, J., \& Miller, H. (1997). Textures and fabrics in the GRIP ice core. Journal of Geophysical Research: Oceans, 102 (C12), 26583e26599. https://doi.org/10.1029/97JC00161 
Urai, J.L., Means, W.D., \& Lister, G.S. (1986). Dynamic recrystallization of minerals. Am. Geophys. Un. Geophys. Monogr. 36, 161-199.

Vaughan, M.J., Prior, D.J., Jefferd, M., Brantut, N., Mitchell, T.M., \& Seidemann, M. (2017). Insights into anisotropy development and weakening of ice from in situ P wave velocity monitoring during laboratory creep. Journal of Geophysical Research: Solid Earth, 122(9), 7076-7089. https://doi.org/10.1002/2017JB013964

Vel, S.S., Cook, A.C., Johnson, S.E., \& Gerbi, C. (2016). Computational homogenization and micromechanical analysis of textured polycrystalline materials. Computer Methods in Applied Mechanics and Engineering, 310, 749-779. https://doi.org/10.1016/j.cma.2016.07.037

Vélez, J.A., Tsoflias, G.P., Black, R.A., Van der Veen, C.J., \& Anandakrishnan, S. (2016). Distribution of preferred ice crystal orientation determined from seismic anisotropy: Evidence from Jakobshavn Isbræ and the North Greenland Eemian Ice Drilling facility, Greenland observation of ice seismic anisotropy. Geophysics, 81(1), 111-118. https://doi.org/10.1190/geo2015-0154.1

Walte, N.P., Bons, P.D., Passchier, C.W., \& Koehn, D. (2003). Disequilibrium melt distribution during static recrystallization. Geology, 31(11), 1009-1012. https://doi.org/10.1130/G19815.1

Watanabe, T. (1993). Effects of water and melt on seismic velocities and their application to characterization of seismic reflectors. Geophysical Research Letters, 20(24), 2933-2936. https://doi.org/10.1029/93GL03170

Weertman, J. (1983). Creep deformation of ice. Annual Review of Earth and Planetary Sciences, 11(1), 215-240.

Weikusat, I., Jansen, D., Binder, T., Eichler, J., Faria, S.H., Wilhelms, F., Kipfstuhl, S., Sheldon, S., Miller, H., Dahl-Jensen, D., \& Kleiner, T. (2017). Physical analysis of an Antarctic ice coretowards an integration of micro-and macrodynamics of polar ice. Philosophical Transactions of the Royal Society A, 375(2086), p.20150347. https://doi.org/10.1098/rsta.2015.0347

Wilhelms, F., Miller, H., Gerasimoff, M.D., Druecker, C., Frenzel, A., Fritzsche, D., Grobe, H., Hansen, S.B., Hoffmann, G., Hörnby, K., \& Jaeschke, A. (2014). The epica dronning maud land deep drilling operation. Annals of Glaciology, 55(68), 355-366.

https://doi.org/10.3189/2014AoG68A189

Wilson, C.J.L., \& Russell-Head, D.S. (1982). Steady-state preferred orientation of ice deformed in plane strain at-1 ${ }^{\circ}$ C. Journal of Glaciology, 28(98), 145-160.

https://doi.org/10.3189/S0022143000011850

Wittlinger, G., \& Farra, V. (2012). Observation of low shear wave velocity at the base of the polar ice sheets: evidence for enhanced anisotropy. Geophysical Journal International, 190(1), 391-405. https://doi.org/10.1111/j.1365-246X.2012.05474.x

Wittlinger, G., \& Farra, V. (2015). Evidence of unfrozen liquids and seismic anisotropy at the base of the polar ice sheets. Polar Science, 9(1), 66-79.

https://doi.org/10.1016/j.polar.2014.07.006

Wolovick, M.J., Creyts, T.T., Buck, W.R., \& Bell, R.E. (2014). Traveling slippery patches produce thickness-scale folds in ice sheets. Geophysical Research Letters, 41(24), 8895-8901. https://doi.org/10.1002/2014GL062248 
von Bargen, N., \& Waff, H.S. (1986). Permeabilities, interfacial areas and curvatures of partially molten systems: results of numerical computations of equilibrium microstructures. Journal of Geophysical Research: Solid Earth, 91(B9), 9261-9276.

https://doi.org/10.1029/JB091iB09p09261

Yoon, Y.J., \& Cowin, S.C. (2009). The elastic moduli estimation of the solid-water mixture.

International Journal of Solids and Structures, 46(3-4), 527-533.

https://doi.org/10.1016/j.ijsolstr.2008.09.010

Zhong, X., Frehner, M., Kunze, K. and Zappone, A., 2014. A novel EBSD-based finite-element wave propagation model for investigating seismic anisotropy: Application to Finero Peridotite, Ivrea-Verbano Zone, Northern Italy. Geophysical Research Letters, 41(20), pp.7105-7114. 